\title{
Ultrasonic-Assisted Extraction Process and Method Validation for Deoxypodophyllotoxin from the Roots of Anthriscus sylvestris: Application of Response Surface Methodology and UPLC-PDA-QDa
}

\author{
Hyo Seon Kim, A Yeong Lee*, Byeong Cheol Moon, Wook Jin Kim and Goya Choi \\ K-herb Research Center, Korea Institute of Oriental Medicine,1672 Yuseong-daero, Yuseong-gu, \\ Daejeon 34054, Republic of Korea
}

Received: 11 October 2017; accepted: 07 December 2017

\begin{abstract}
Deoxypodophyllotoxin (DPT), or anthricin, is a lignan isolated from the roots of Anthriscus sylvestris and is reported to exhibit anti-inflammatory, anti-oxidant, and anti-asthmatic effects. Herein, the conditions for the extraction of DPT from A. sylvestris are optimized using a Box-Behnken design (BBD) method based on response surface methodology (RSM). DPT was detected by ultra-performance liquid chromatography coupled with photodiode array and quadrupole detector (UPLC-PDA-QDa) and analytical validation methods based on International Conference on Harmonization (ICH) guidelines. In preliminary experiments, the experimental conditions of extraction time, solvent percentage, and temperature were selected for optimization. The adequacy of the experimental model was statistically evaluated, and the regression coefficient $\left(R^{2}\right)$, adjusted regression coefficient $\left(R_{\text {adjust }}^{2}\right)$, and $p$-value of the lack-of-fit were determined as $97.86 \%, 94.02 \%$, and 0.124 , respectively. The maximum yield of DPT was estimated to be $2.341 \mathrm{mg} / \mathrm{g}$ for 30 min in $100 \%$ methanol at $60{ }^{\circ} \mathrm{C}$, and the actual yield was measured as $2.295 \mathrm{mg} / \mathrm{g}( \pm 0.023)$ under the same conditions.

Keywords: Anthriscus sylvestris, deoxypodophyllotoxin, optimization, response surface methodology, UPLC-PDA-QDa
\end{abstract}

\section{Introduction}

Anthriscus sylvestris (L.) Hoffm., commonly known as wild chervil or cow parsley, belongs to the Apiaceae family and is traditionally used as an antitussive, antipyretic, analgesic, diuretic, and cough remedy in many countries [1]. The roots of $A$. sylvestris contain monoterpenes [2], lignans [3], coumarins, phenylpropene, and polyacetylene derivatives [1]. The most effective compound found in $A$. sylvestris roots is the lignan deoxypodophyllotoxin (DPT), which is reported to elicit anti-lung inflammation [4], antitumor [1], anti-proliferative, and anti-viral activities [5].

The distinct advantages of DPT as a therapeutic agent, as well as other active ingredients in A. sylvestris, warrant its extraction in high yields so that such compounds can be effectively used in the food industry. For this purpose, various extraction factors and methods have been studied such as Soxhlet extraction, solvent extraction, microwave-assisted extraction, supercritical fluid extraction, and ultrasonic-assisted extraction [6]. Among them, ultrasonic-assisted extraction has been used in the food industry and to extract phytochemical ingredients $[7,8]$ because, relative to other methods, it is eco-friendly, cost-effective, and requires relatively less time, energy, and solvent; it also has a low physical risk and enhanced extraction quality [8].

Some of the extraction factors that must be considered include time, temperature, $\mathrm{pH}$, particle size, pressure, solvent type, and concentration [9]. The traditional approach of "onevariable-at-a-time" is well accepted, but it is time-consuming and requires significant effort [9]. Moreover, this approach does not consider the effect of interactions among different factors [10]. To overcome these shortcomings, Box and Wilson suggested the use of response surface methodology (RSM) [11]. RSM is an effective and efficient mathematical statistics method to construct models, evaluate the effects of multiple variables, and determine the optimal conditions to obtain desirable

* Author for correspondence: lay7709@kiom.re.kr responses; collectively, this approach helps to overcome the limitations of conventional methods [12]. The main advantage of RSM is the reduced number of experimental trials required to evaluate multiple parameters and their interactions [13].

In this study, components from the roots of $A$. sylvestris are extracted using RSM with a Box-Behnken design (BBD). The experimental factors selected for investigation were extraction time, temperature, and percentage of methanol in distilled water, with preliminary tests based on the one-variable-at-a-time approach. Notably, the active component DPT was detected by ultra-performance liquid chromatography (UPLC) within $5.0 \mathrm{~min}$ and validated according to the International Conference on Harmonization (ICH) guidelines.

\section{Experimental}

Plant Materials and Chemicals. Dried roots of $A$. sylvestris were purchased from an oriental pharmacy in Jeollanamdo, South Korea. Their morphology and genetic identification were determined by Drs. Goya Choi and Byeong Cheol Moon, respectively, at the Korea Institute of Oriental Medicine (KIOM). A voucher specimen was deposited in the Korean Herbarium of Standard Herbal Resources at KIOM (Index herbariorum code KIOM, Specimen No. KIOM 2-15-0480). A fine powder of the material was obtained after grinding and passing it through a $600 \mu \mathrm{m}$ sieve.

DPT $(>95.0 \%)$ was obtained from the National Development Institute of Korean Medicine (Gyeongsangbuk-do, South Korea), and podophyllotoxin (PD; $\geq 98 \%)$ and yatein $(\geq 98 \%)$ were obtained from ChemFace (Hubei, China). The structures of these chemicals are represented in Figure 1. High-performance liquid chromatography (HPLC) grade solvents were purchased from J.T. Baker Inc. (Phillipsburg, NJ, USA).

Genetic Authentication of Plant Materials. The genomic DNA of authentic control plants and samples were extracted

This is an open-access article distributed under the terms of the Creative Commons Attribution-NonCommercial 4.0 International License (https://creativecommons.org/licenses/by-nc/4.0/), which permits unrestricted use, distribution, and reproduction in any medium for non-commercial purposes, provided the original author and source are credited, a link to the CC License is provided, and changes - if any - are indicated. 
<smiles>COc1cc([C@@H]2Cc3cc4c(cc3[C@@H]2[C@H]2CCOC2=O)OCO4)cc(OC)c1OC</smiles>

(A)<smiles></smiles>

(B)<smiles>COc1cc(C[C@H]2CCOC2=O)cc(OC)c1OC</smiles>

(C)

Figure 1. Chemical structure of deoxypodophyllotoxin (A), podophyllotoxin (B), and yatein (C)

using the DNeasy Plant Mini Kit (GIAGEN, USA) following the manufacturer's protocol. To verify the plant species, multiplex polymerase chain reaction (PCR) was carried out using six combinations of species-specific Sequence Characterized Amplified Region (SCAR) primers and the total genomic DNA, as described in a previous report [14]. After gel electrophoresis of the PCR products, we compared the size and specificity of the resultant DNA bands with those of control DNA extracted from authentic plant materials (Figure 2) [14].

Extraction Procedure. An aliquot of the powdered sample $(0.2 \mathrm{~g})$ to be extracted was placed in $10 \mathrm{~mL}$ of the appropriate solvent $(n=5)$, capped in a vial, and subjected to an ultrasonic bath (44 kHz, 8510 Ultrasonic; Bransonic Co., Danbery, CT, USA). The extract was filtered through a $0.2 \mu \mathrm{m}$ membrane syringe filter before injection into the UPLC system.

UPLC Analysis. Identification of the chemical patterns and the analysis of the optimal experimental conditions was performed using a UPLC-photodiode array (PDA)quadrupole detector (QDa) instrument. The UPLC system (Acquity $^{\mathrm{TM}}$ UPLC system; Waters Corporation, Milford, MA, USA) comprised a binary solvent pump, sample manager, column oven, online degasser, PDA detector, and QDa detector. The UPLC data were processed with Empower ${ }^{\mathrm{TM}} 3$ software (Waters Corporation). The analytical column

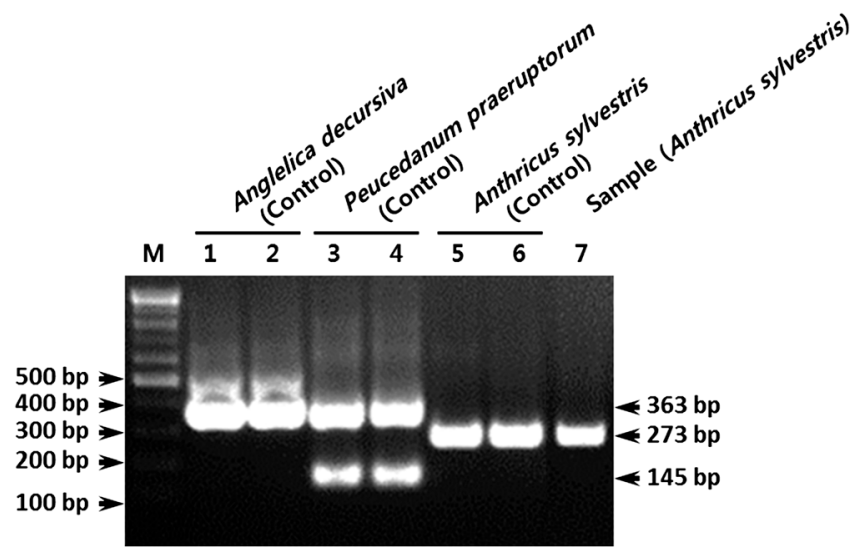

Figure 2. Authentication of plant material based on the multiplexSCAR marker. Line 1-2, line 3-4, line 5-6, and line 7 indicate the PCR product form authentic $A$. decursiva, P. praeruptorum, A. sylvestris, and root of $A$. sylvestris used in this study, respectively. The size of precise PCR products and DNA ladders is represented by the arrowheads at the right and left side of gel image, respectively. M represents $100 \mathrm{bp}$ DNA ladder comprised an Acquity UPLC ${ }^{\circledR}$ ethylene-bridged hybrid (BEH) $\mathrm{C}_{18}$ column $(2.1 \times 150 \mathrm{~mm}, 1.7 \mu \mathrm{m}$; Waters Corporation $)$. The mobile phase was $0.05 \%$ formic acid containing distilled water (A) and methanol (B). The linear gradient conditions of the mobile phase for pattern analysis began with $40 \%$ methanol and changed to $100 \%$ methanol over $30 \mathrm{~min}$. The optimization conditions included an isocratic mobile phase comprising $62 \%$ methanol for $5 \mathrm{~min}$ at a flow rate of $0.2 \mathrm{~mL} / \mathrm{min}$ and an injection volume of $2 \mu \mathrm{L}$. The wavelengths were monitored at $200-400 \mathrm{~nm}$, and the sample peak was detected at $290 \mathrm{~nm}$. The sample peaks were confirmed with a standard peak in terms of retention time and consistency with ultraviolet (UV) wavelength and MS spectrum analyses. Nitrogen was used as the carrier gas for the QDa detector under the following conditions: mass condition, $\mathrm{m} / \mathrm{z}$ range of $350-450$; capillary voltage, $0.8 \mathrm{~V}$; probe temperature, $600{ }^{\circ} \mathrm{C}$; sampling frequency, $8 \mathrm{~Hz}$; cone voltage, $15 \mathrm{~V}$; source temperature, $120^{\circ} \mathrm{C}$; and turbo temperature, $45^{\circ} \mathrm{C}$. The selective ion recording (SIR) of DPT was monitored at $\mathrm{m} / \mathrm{z} 421$ in positive mode.

Method Validation. The DPT standard compound was dissolved in methanol. The linearity of DPT $(6.25,12.5,25,50$, and $100 \mu \mathrm{g} / \mathrm{mL}$ ) was established via a correlation coefficientderived calibration curve. The relative standard deviation (RSD) was calculated as $\mathrm{SD} /$ mean $\times 100$. The limit of detection (LOD) and limit of quantitation (LOQ) of DPT were computed as $3.3 \sigma / \mathrm{s}$ and $10 \sigma / s$, respectively, where $\sigma$ is the SD of the response and $s$ is the slope of the calibration curve. Both intra-day $(n=6)$ and inter-day precision and accuracy of DPT were determined over three consecutive days. The recovery tests were conducted at high, medium, and low spiking concentrations using the relation $\{($ detected concentration - initial concentration $) /$ spiked concentration $\} \times 100$.

Preliminary Conditions. To select the optimal experimental conditions, the sample was extracted using the one-variable-at-atime method by considering the following factors: solvent type, extraction time, temperature, and solvent percentage. Water, ethanol, and methanol were selected as the solvents because they have low toxicity and are eco-friendly. The extraction time and temperature were set to $10-70 \mathrm{~min}$ and $30-60 \pm 2{ }^{\circ} \mathrm{C}$, respectively. Finally, $40-100 \%(v / v)$ methanol containing distilled water was chosen as the solvent. Statistical analyses (i.e., $t$-test, one-way ANOVA, and Kruskal-Wallis test [15]) were performed using GraphPad Prism 6 (GraphPad Software, Inc., La Jolla, CA, USA) and Minitab 16.0 (Minitab Inc., State College, PA, USA).

RSM Design. The most widely used RSM designs comprise a central composite design (CCD) and a BBD. These designs 

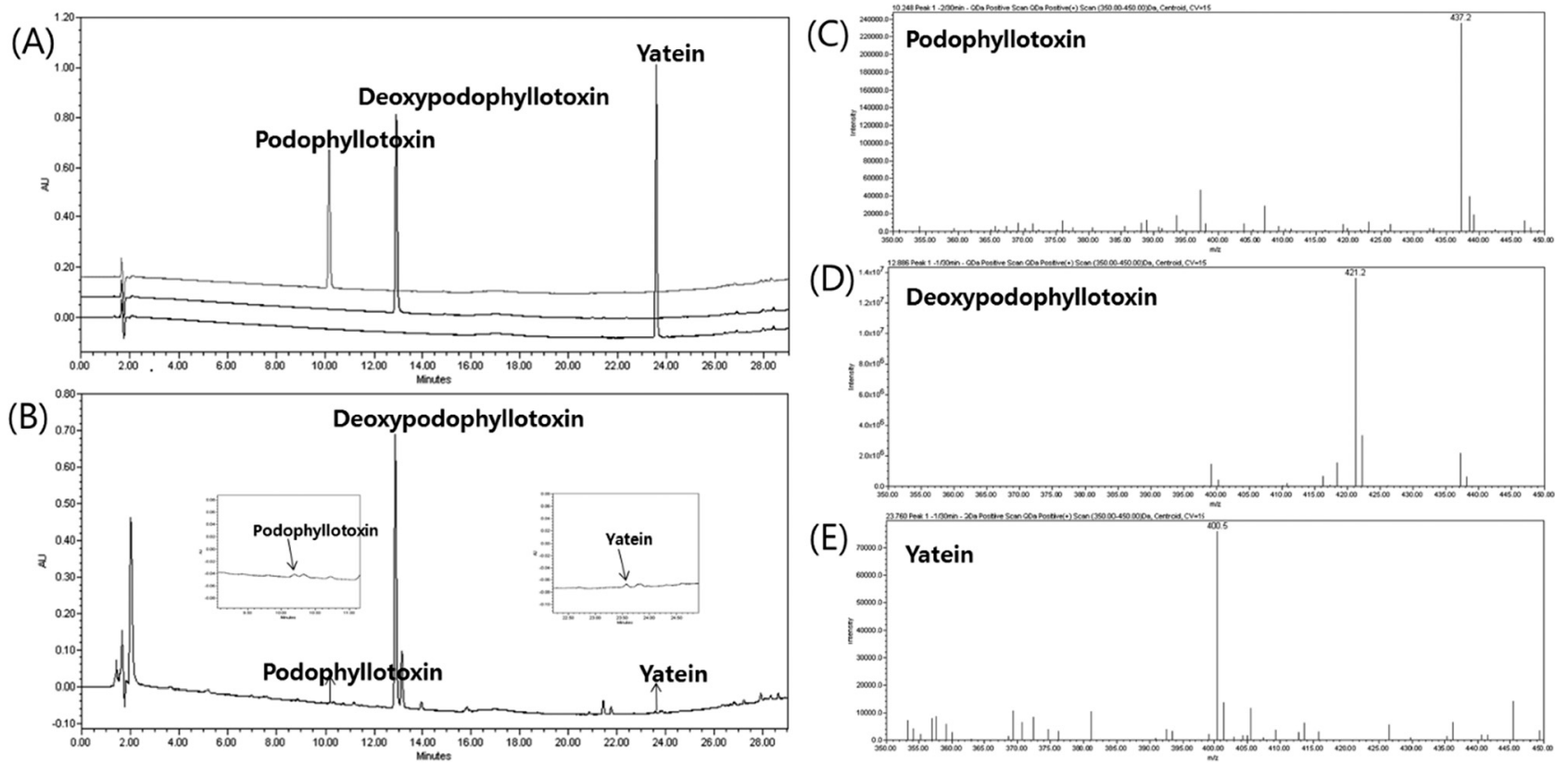

Figure 3. Chemical profiling for root of A. sylvestris; standard components of chromatogram (A), sample chromatogram (B), mass spectra of podophyllotoxin $(\mathrm{C})$, deoxypodophyllotoxin $(\mathrm{D})$, and yatein $(\mathrm{E})$

were used to identify the relationship between the independent factors and the dependent variables [16]. BBD has been widely used in the optimization of bioactive compounds [17] and to determine the best combination of extraction variables for determining DPT yields [13]. The Minitab BBD includes variables with codes $-1,0$, and 1 . The three variables considered in this study were extraction time $\left(X_{1} ; 30,45\right.$, and $\left.60 \mathrm{~min}\right)$, methanol percentage $\left(X_{2} ; 50 \%, 75 \%\right.$, and $\left.100 \%\right)$, and extraction temperature $\left(X_{3} ; 40,55\right.$, and $\left.70{ }^{\circ} \mathrm{C}\right)$, and the range of these factors was determined by a preliminary experiment. This experimental design consisted of a total of 15 variable configuration points, with each point repeated in 5 times. The data were fitted to a quadratic polynomial model and the regression coefficients were obtained [13]. The polynomial equation was as follows:

$$
Y=\beta_{0}+\sum_{i=1}^{3} \beta_{i} X_{i}+\sum_{i=1}^{3} \beta_{i i} X_{i}^{2}+\sum_{i<j=1}^{3} \beta_{i j} X_{i} X_{j}+\varepsilon
$$
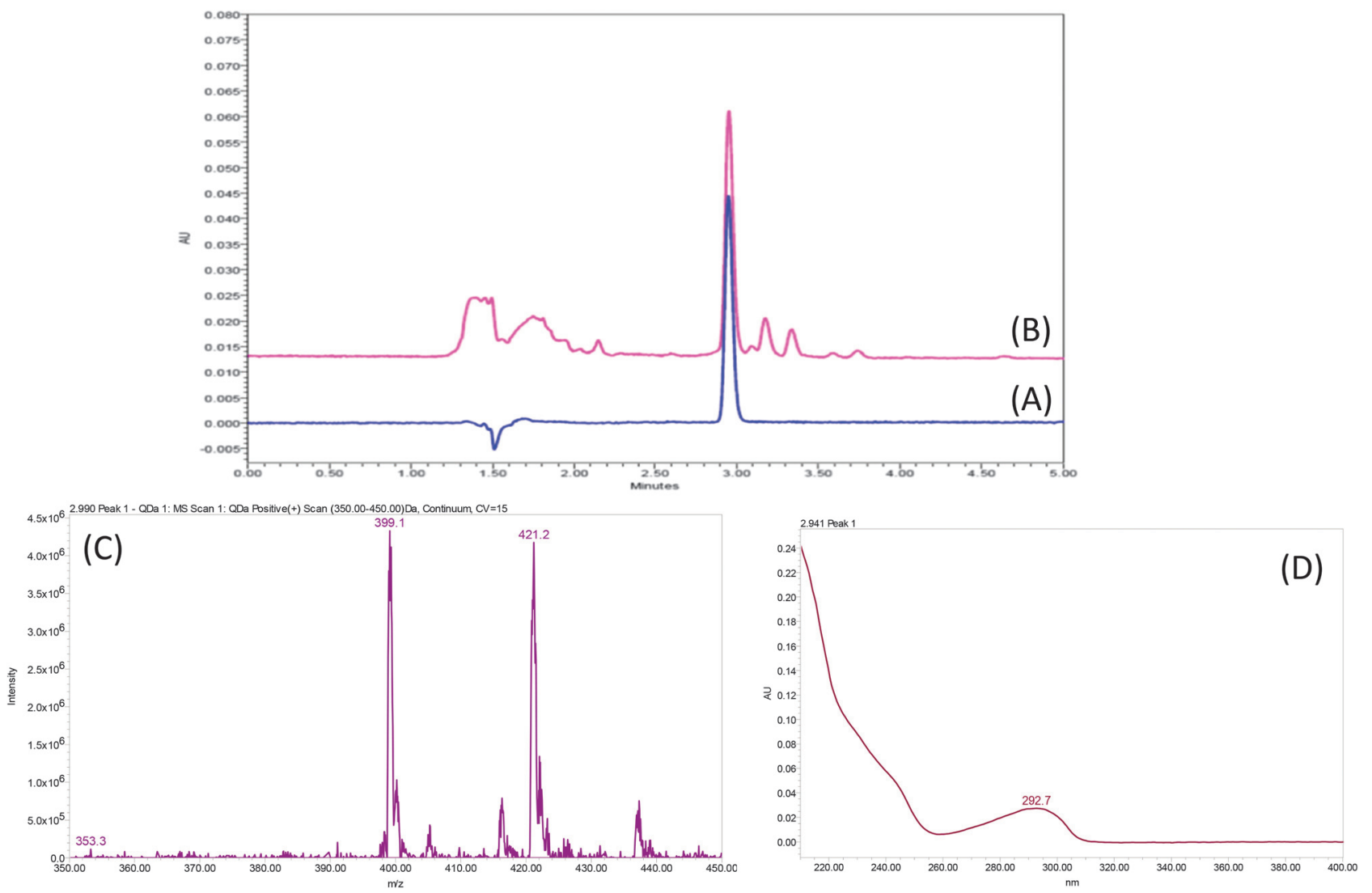

Figure 4. Chromatogram of DPT standard (A), methanol extraction of A. sylvestris (B) at $290 \mathrm{~nm}$, mass spectrum (C), and UV spectrum of DPT (D) 
Table 1. Intra-day and inter-day precision for DPT

\begin{tabular}{ccccccc}
\hline \multirow{2}{*}{$\begin{array}{c}\text { Concentration } \\
(\mu \mathrm{g} / \mathrm{mL})\end{array}$} & \multicolumn{2}{c}{ Intra-day $(n=6)$} & & \multicolumn{2}{c}{ Inter-day $(n=6)$} \\
\cline { 3 - 4 } & 50 & $\begin{array}{c}\text { Found } \\
(\mu \mathrm{g} / \mathrm{mL})\end{array}$ & $\begin{array}{c}\text { RSD } \\
(\%)\end{array}$ & & $\begin{array}{c}\text { Found } \\
(\mu \mathrm{g} / \mathrm{mL})\end{array}$ & $\begin{array}{c}\text { RSD } \\
(\%)\end{array}$ \\
\hline $\mathrm{DPT}$ & 50.7 & 0.45 & & 51.4 & 1.72 \\
& 25 & 25.6 & 0.74 & & 25.9 & 1.19 \\
& 12.5 & 12.3 & 1.17 & & 12.4 & 0.92 \\
\hline
\end{tabular}

where $Y$ is the dependent or response variable; $\varepsilon$ is the residual term; $\beta_{0}, \beta_{i}, \beta_{i i}$, and $\beta_{i j}$ are the intercept, linear, quadratic, and interaction coefficients, respectively; and $X_{i}$ and $X_{j}$ are the independent variables [15].

\section{Results and Discussion}

UPLC Analysis and Method Validation. The chromatograms of $A$. sylvestris containing DPT, PD, and yatein are shown in Figure 3. As seen, PD, DPT, and yatein were detected at approximately $10.1,12.4$, and $23.8 \mathrm{~min}$, respectively, and their corresponding values of selective ion recording (SIR) in positive mode were $437.2 \mathrm{~m} / \mathrm{z}[\mathrm{M}+\mathrm{Na}]^{+}, 421.2 \mathrm{~m} / \mathrm{z}[\mathrm{M}+\mathrm{Na}]^{+}$, and $400.5 \mathrm{~m} / \mathrm{z}[\mathrm{M}]^{+}$, respectively. The contents of PD, DPT, and yatein were $0.011\left( \pm 2.51 \times 10^{5}\right), 2.235( \pm 0.007)$, and $0.014\left( \pm 2.86 \times 10^{5}\right) \mathrm{mg} / \mathrm{g}$, respectively. The optimization procedure of the method was performed for DPT only because of the trace contents of PD and yatein (Figure 3).

Chromatograms of DPT in A. sylvestris are represented in Figure 4. As seen, DPT was detected at $2.951( \pm 0.002)$ min with a wavelength of $292.7 \mathrm{~nm}$. The total ion chromatogram (TIC) in positive mode at $350-450 \mathrm{~m} / \mathrm{z}$ and selective ion recording (SIR) mode identified $[\mathrm{M}+\mathrm{Na}]^{+}$at $421 \mathrm{~m} / \mathrm{z}$. The standard curve indicated good linearity, and the standard range, linear equation, and correlation coefficient were $6.25-100 \mu \mathrm{g} / \mathrm{mg}, Y=6414.3784 X+$ 11343.9028 , and $R^{2}=0.9997$, respectively. The LOD and LOQ of DPT were 0.0479 and $0.1451 \mu \mathrm{g} / \mathrm{mL}$, respectively.

The values of the inter-day $(0.92-1.72 \%)$ and intra-day $(0.45-1.17 \%)$ precision of DPT were acceptable, with RSD $\leq$ $2.0 \%$ (Table 1). Inter- and intra-day recovery tests had values of $101.202-105.040 \%$ and $101.693-105.729 \%$, respectively, and all precision and recovery RSD values were less than $2.0 \%$ (Table 2).

Preliminary Extraction Conditions. A. sylvestris was extracted in distilled water, methanol, and ethanol. Distilled water was chosen because of its widespread availability and nontoxicity compared with methanol and ethanol $[18,19]$. DPT did not dissolve in distilled water. The yields of DPT in methanol and ethanol were $2.366 \pm 0.078$ and $2.105 \pm 0.025 \mathrm{mg} / \mathrm{g}$, respectively ( $t$-test, $p=0.031$ ). Given the higher yield of DPT in methanol, this solvent was selected as the optimal solvent (Figure 5A). Although DPT was not detected in either $0 \%$ or $20 \%$ methanol, its yields in $40 \%, 60 \%, 80 \%$, and $100 \%$ methanol were detected as $2.100 \pm 0.102,2.386 \pm 0.039$, $2.404 \pm 0.017$, and $2.407 \pm 0.038 \mathrm{mg} / \mathrm{g}$, respectively (KruskalWallis). Based on these results, a methanol range of $50-100 \%$ was selected for the subsequent studies (Figure 5B).

The DPT contents after extraction for $10,20,30,40,50$, 60 , and $70 \mathrm{~min}$ were $2.346 \pm 0.086,2.366 \pm 0.047,2.206 \pm$ $0.043,2.354 \pm 0.020,2.513 \pm 0.056,2.520 \pm 0.018$, and $2.523 \pm 0.014 \mathrm{mg} / \mathrm{g}$, respectively (one-way ANOVA, post-hoc by Tukey's test). The range of the extraction time was

Table 2. Intra-day and inter-day recovery test of DPT

\begin{tabular}{|c|c|c|c|c|c|c|c|c|c|}
\hline & \multirow{2}{*}{$\begin{array}{c}\text { Spike } \\
\text { concentration } \\
(\mu \mathrm{g} / \mathrm{mL})\end{array}$} & \multicolumn{4}{|c|}{ Intra-day $(n=6)$} & \multicolumn{4}{|c|}{ Inter-day $(n=6)$} \\
\hline & & $\begin{array}{c}\text { Initial } \\
\text { concentration } \\
(\mu \mathrm{g} / \mathrm{mL})\end{array}$ & $\begin{array}{c}\text { Detected } \\
\text { concentration } \\
(\mu \mathrm{g} / \mathrm{mL})\end{array}$ & $\begin{array}{c}\text { Recovery } \\
(\%)\end{array}$ & $\begin{array}{c}\text { RSD } \\
(\%)\end{array}$ & $\begin{array}{c}\text { Initial } \\
\text { concentration } \\
(\mu \mathrm{g} / \mathrm{mL})\end{array}$ & $\begin{array}{c}\text { Detected } \\
\text { concentration } \\
(\mu \mathrm{g} / \mathrm{mL})\end{array}$ & $\begin{array}{c}\text { Recovery } \\
(\%)\end{array}$ & $\begin{array}{c}\text { RSD } \\
(\%)\end{array}$ \\
\hline$\overline{\mathrm{DPT}}$ & $\begin{array}{c}25 \\
12.5 \\
6.25\end{array}$ & $\begin{array}{l}10.931 \\
10.931 \\
10.931\end{array}$ & $\begin{array}{l}36.363 \\
24.451 \\
18.047\end{array}$ & $\begin{array}{l}101.202 \\
104.353 \\
105.040\end{array}$ & $\begin{array}{l}0.267 \\
0.439 \\
0.208\end{array}$ & $\begin{array}{l}10.946 \\
10.946 \\
10.946\end{array}$ & $\begin{array}{l}36.555 \\
24.599 \\
18.182\end{array}$ & $\begin{array}{l}101.693 \\
104.915 \\
105.729\end{array}$ & $\begin{array}{l}0.459 \\
1.011 \\
0.986\end{array}$ \\
\hline
\end{tabular}
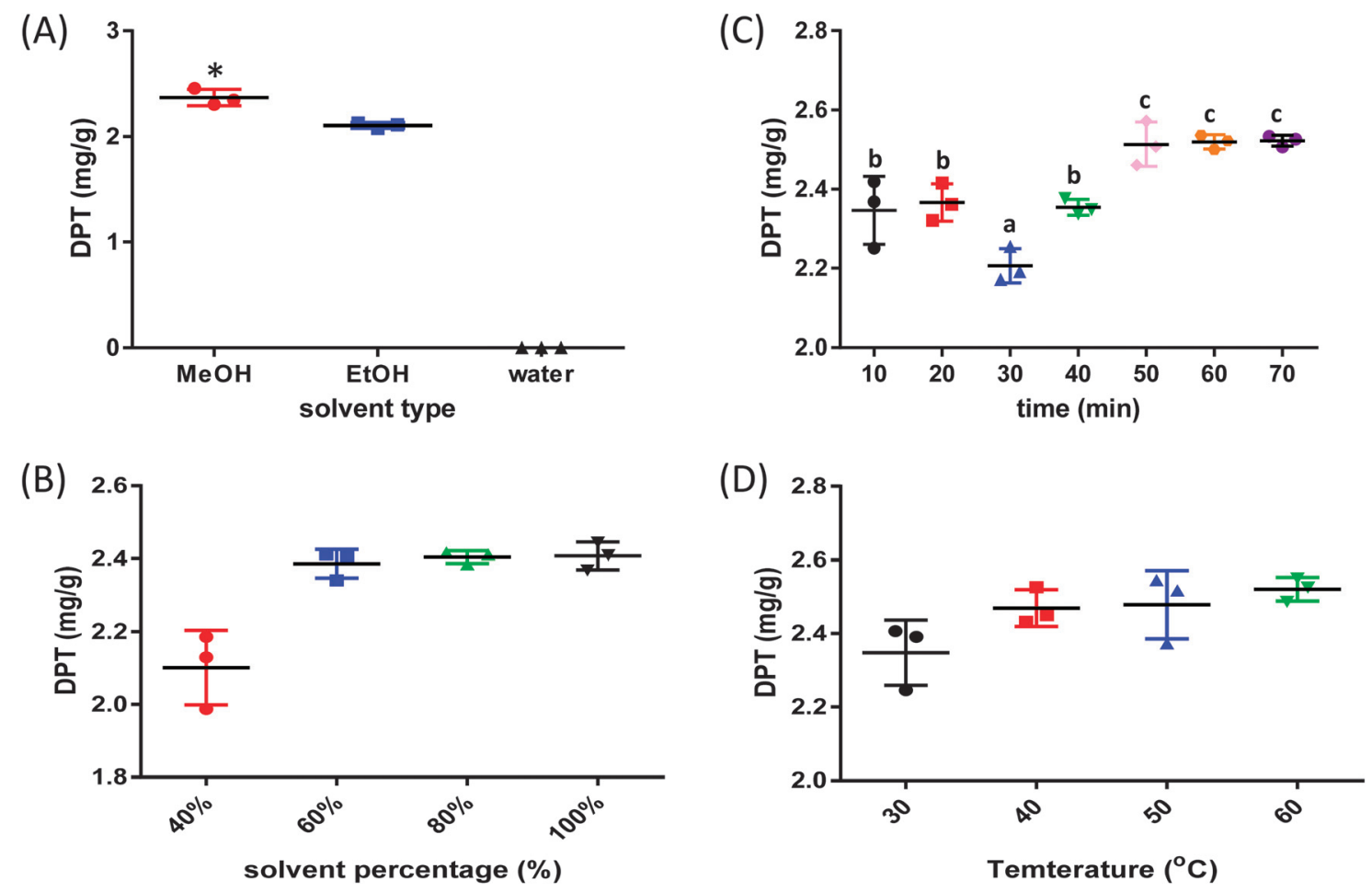

Figure 5. The content of DPT for solvents type, times, temperatures, and solvent percentage (ratio of methanol and distilled water). ${ }^{*} p<0.05$ by $t$-test (without water). ${ }^{\mathrm{a}, \mathrm{b}, \mathrm{c}}$ Post-hoc by Tukey 
delimited to 30-60 $\mathrm{min}$ because 60 and $70 \mathrm{~min}$ were not statistically significant (Figure 5C).

The yields of DPT at extraction temperatures of $30,40,50$, and $60{ }^{\circ} \mathrm{C}$ were $2.348 \pm 0.088,2.469 \pm 0.050,2.478 \pm 0.092$, and $2.521 \pm 0.032 \mathrm{mg} / \mathrm{g}$, respectively (Kruskal-Wallis). Clearly, the DPT content increased as the temperature increased (Figure 5D). The temperature was maintained between 40 and $70{ }^{\circ} \mathrm{C}$. Note that this temperature range includes the boiling point of methanol $\left(64.7^{\circ} \mathrm{C}\right)$.

Fitted Model. The contents of DPT based on the BBD factors are listed in Table 3. The DPT yield ranged from $2.108 \pm$ 0.049 to $2.344 \pm 0.031 \mathrm{mg} / \mathrm{g}$. The DPT content under various conditions was calculated by one-way ANOVA, which includes the regression coefficient $\left(R^{2}\right)$ of the second-order polynomial equation (Table 4). The fitness of the quadratic polynomial model was verified by $R^{2}$ values [20]. The quality of the fit of the polynomial model equation was expressed by the coefficient of determination $R^{2}$, and the significance of the regression coefficient was checked by the corresponding $F$-test and $p$-value estimates [13]. As is well known, the value of $R^{2}$ always ranges between 0 and 1 , and a model is more predictive when its $R^{2}$ value is closer to 1 [21]. In this model, the $R^{2}$ and $R_{\text {adjust values }}^{2}$ of DPT were $97.86 \%$ and $94.02 \%$, respectively. In a valid statistical model, the $R_{\text {adjust }}^{2}$ and $R^{2}$ values should be close [20]. This model could be used to show why $R^{2}$ should be close to $R_{\text {adjust }}^{2}$ in a good model. The $p$-value of the lack-of-fit was 0.124 , and the $F$-test suggests that the model had a high $F$-value and low $p$-value [13]. Overall, these results $(p>0.05)$ demonstrate that the quadratic model was valid within the spatial influence of the variables on the response [15].

Table 3. Box-Behnken design matrix and experimental results from the response variables $(n=5)$

\begin{tabular}{lrrrc}
\hline No. & $X_{1}(\mathrm{~min})$ & $X_{2}(\mathrm{v} / \mathrm{v})$ & $X_{3}\left({ }^{\circ} \mathrm{C}\right)$ & DPT $(\mathrm{mg} / \mathrm{g})$ \\
\hline 1 & $30(-1)$ & $50(-1)$ & $55(0)$ & $2.164( \pm 0.034)$ \\
2 & $60(1)$ & $50(-1)$ & $55(0)$ & $2.211( \pm 0.028)$ \\
3 & $30(-1)$ & $100(1)$ & $55(0)$ & $2.297( \pm 0.043)$ \\
4 & $60(1)$ & $100(1)$ & $55(0)$ & $2.344( \pm 0.031)$ \\
5 & $30(-1)$ & $75(0)$ & $40(-1)$ & $2.230( \pm 0.033)$ \\
6 & $60(1)$ & $75(0)$ & $40(-1)$ & $2.237( \pm 0.017)$ \\
7 & $30(-1)$ & $75(0)$ & $70(1)$ & $2.241( \pm 0.024)$ \\
8 & $60(1)$ & $75(0)$ & $70(1)$ & $2.263( \pm 0.053)$ \\
9 & $45(0)$ & $50(-1)$ & $40(-1)$ & $2.108( \pm 0.049)$ \\
10 & $45(0)$ & $100(1)$ & $40(-1)$ & $2.236( \pm 0.027)$ \\
11 & $45(0)$ & $50(-1)$ & $70(1)$ & $2.148( \pm 0.047)$ \\
12 & $45(0)$ & $100(1)$ & $70(1)$ & $2.299( \pm 0.030)$ \\
13 & $45(0)$ & $75(0)$ & $55(0)$ & $2.274( \pm 0.014)$ \\
14 & $45(0)$ & $75(0)$ & $55(0)$ & $2.287( \pm 0.048)$ \\
15 & $45(0)$ & $75(0)$ & $55(0)$ & $2.276( \pm 0.041)$ \\
\hline
\end{tabular}

Table 4. Analyses of the regression model with a dependent $Y$ variable for the extraction conditions

\begin{tabular}{lccrc}
\hline Variable & \multicolumn{3}{c}{$\mathrm{DPT}\left(R^{2}=97.86 \%, R^{2}{ }_{\text {(adjust) }}=94.02 \%\right)$} \\
\cline { 2 - 5 } & $\mathrm{DF}$ & Sum of squares & $F$-value & $P$-value \\
\hline Regression & 9 & 0.054411 & 25.44 & 0.001 \\
Linear & 3 & 0.041648 & 58.41 & 0.000 \\
$X_{1}$ & 1 & 0.001889 & 7.95 & 0.037 \\
$X_{2}$ & 1 & 0.037324 & 157.03 & 0.000 \\
$X_{3}$ & 1 & 0.002434 & 10.24 & 0.024 \\
Square & 3 & 0.012585 & 17.65 & 0.004 \\
$X_{1} X_{1}$ & 1 & 0.000894 & 1.44 & 0.283 \\
$X_{2} X_{2}$ & 1 & 0.003717 & 19.26 & 0.007 \\
$X_{3} X_{3}$ & 1 & 0.007974 & 33.55 & 0.002 \\
Interaction & 3 & 0.000179 & 0.25 & 0.858 \\
$X_{1} X_{2}$ & 1 & 0.000000 & 0.00 & 0.995 \\
$X_{1} X_{3}$ & 1 & 0.000048 & 0.20 & 0.671 \\
$X_{2} X_{3}$ & 1 & 0.000131 & 0.55 & 0.492 \\
Residual error & 5 & 0.001188 & & \\
Lack of fit & 3 & 0.001088 & 7.22 & 0.124 \\
Pure error & 2 & 0.000100 & & \\
Total & 14 & 0.055600 & & \\
\hline
\end{tabular}

The linear and square terms of DPT included large $F$-values $(58.41,17.65)$ and small $p$-values $(0.000,0.004)$; however, the interaction terms included a small $F$-value $(0.25)$ and a large $p$-value (0.858). This result suggests that the yield of DPT was influenced by the linear and square terms more than the interaction term.

RSM. As the main active compound of A. sylvestris, the amount of DPT extracted and detected was optimized in this study. In the food and pharmaceutical industries, ultrasonicassisted extraction and RSM are powerful approaches with many advantages [15]. In this study, BBD was used in conjunction with $\mathrm{CCD}$, which is a common approach. The quadratic model was computed as a second-order polynomial equation, with extraction time $\left(X_{1}, \mathrm{~min}\right)$, solvent percentage $\left(X_{2}, \%\right)$, and extraction temperature $\left(X_{3},{ }^{\circ} \mathrm{C}\right)$ as variables:

$$
\begin{aligned}
Y= & -3.692 \times 10^{-3} X_{1}+1.034 \times 10^{-2} X_{2}+0.220 \times 10^{-1} X_{3} \\
& +4.286 \times 10^{-5} X_{1}^{2}-5.633 \times 10^{-5} X_{2}^{2}-2.065 \\
& \times 10^{-4} X_{3}^{2}+1.360 \times 10^{-7} X_{1} X_{2}+1.543 \times 10^{-5} X_{1} X_{3} \\
& +2.524 \times 10^{-5} X_{2} X_{3}+1.211
\end{aligned}
$$

The regression coefficients for DPT are tabulated in Table 5. All linear terms (time, percentage, and temperature) and two square terms (percentage $\times$ percentage and temperature $\times$ temperature) were significant for DPT, with $p$-values of 0.037 , $0.000,0.024,0.007$, and 0.002 , respectively. However, not all of the interaction terms were significant. The $p$-value was used as a measure of the significance of each coefficient and indicates correlated interactions between variables [22]. Small $p$-values indicate that the DPT extraction yield is influenced by the associated variables [7]. In this work, time, percentage, temperature, percentage $\times$ percentage, and temperature $\times$ temperature were found to affect the DPT extraction efficiency.

The quadratic model of BBD can be shown as 3D surface plots and $2 \mathrm{D}$ contour images for interactions among the three variables (i.e., $X_{1}$, extraction time; $X_{2}$, methanol percentage; and $X_{3}$, extraction temperature). The response curves were plotted to understand the interactions among the variables and to determine the optimum level of each variable for maximum response [23]. Figure 6 shows the 2D contour and 3D surface plots of DPT for the response variables. The three surface plots exhibited the highest yield at $55-65{ }^{\circ} \mathrm{C}, 55-60 \mathrm{~min}$, and $80-100 \%$ methanol. These data indicate that the DPT content increased as the methanol content increased. Additionally, the DPT content tends to decrease after $55-65^{\circ} \mathrm{C}$. This may occur because increasing the extraction temperature accelerates the chemical decomposition of DPT owing to the durative ultrasonic effect, which causes lower extraction yields [6, 24]. Figure 7 shows the optimal conditions for DPT; at 60 min, $59.4{ }^{\circ} \mathrm{C}$, and $100 \%$ methanol, the DPT content was

Table 5. Regression coefficients result from the data of BBD experiments

\begin{tabular}{lrrrr}
\hline Variable & \multicolumn{4}{c}{ DPT } \\
\cline { 2 - 5 } & Coefficient & $\begin{array}{c}\text { Standard error } \\
\text { coefficient }\end{array}$ & $T$-value & $P$-value \\
\hline Constant & 2.27940 & 0.008901 & 256.084 & 0.000 \\
$X_{1}$ & 0.01537 & 0.005451 & 2.819 & 0.037 \\
$X_{2}$ & 0.06830 & 0.005451 & 12.531 & 0.000 \\
$X_{3}$ & 0.01744 & 0.005451 & 3.200 & 0.024 \\
$X_{1} X_{1}$ & 0.00964 & 0.008023 & 1.202 & 0.283 \\
$X_{2} X_{2}$ & -0.03521 & 0.008023 & -4.388 & 0.007 \\
$X_{3} X_{3}$ & -0.04647 & 0.008023 & -5.792 & 0.002 \\
$X_{1} X_{2}$ & 0.00005 & 0.007708 & 0.007 & 0.995 \\
$X_{1} X_{3}$ & 0.00347 & 0.007708 & 0.450 & 0.671 \\
$X_{2} X_{3}$ & 0.00571 & 0.007708 & 0.741 & 0.492 \\
\hline
\end{tabular}


(A) Contour Plot of DPT vs temperature, time

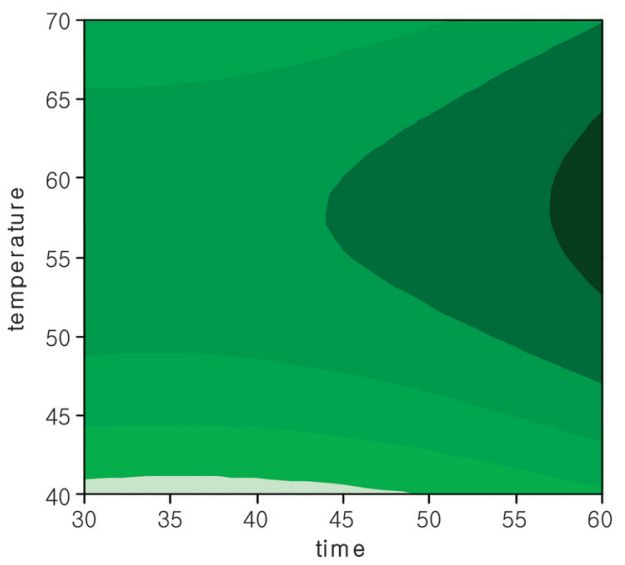

(B) Contour Plot of DPT vs temperature, percentage

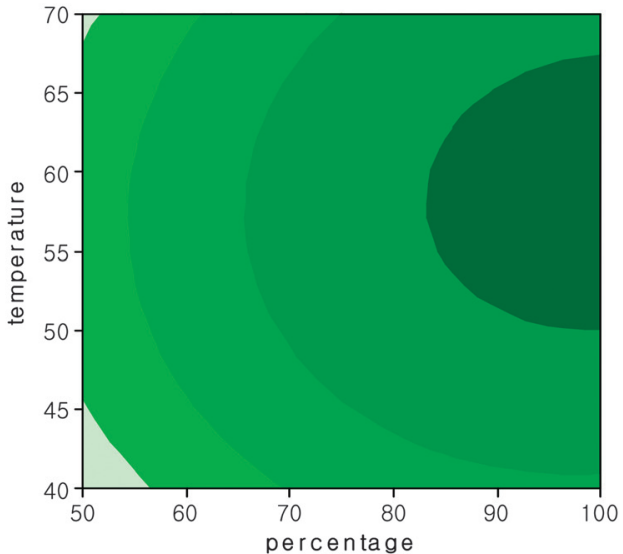

(C) Contour Plot of DPT vs percentage, time

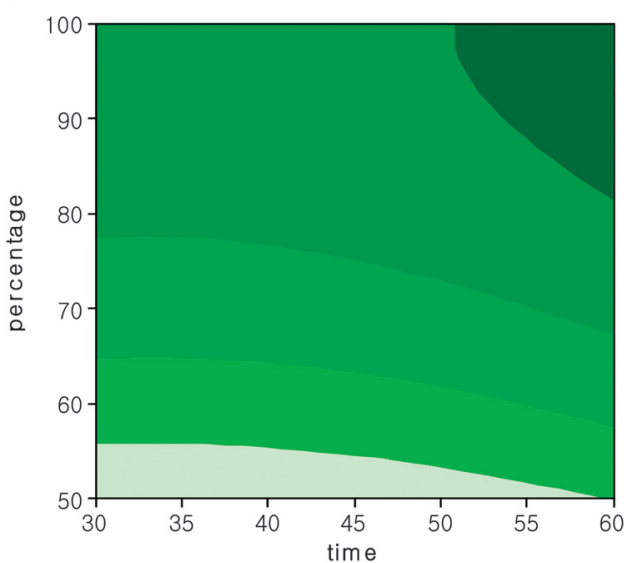

(D)

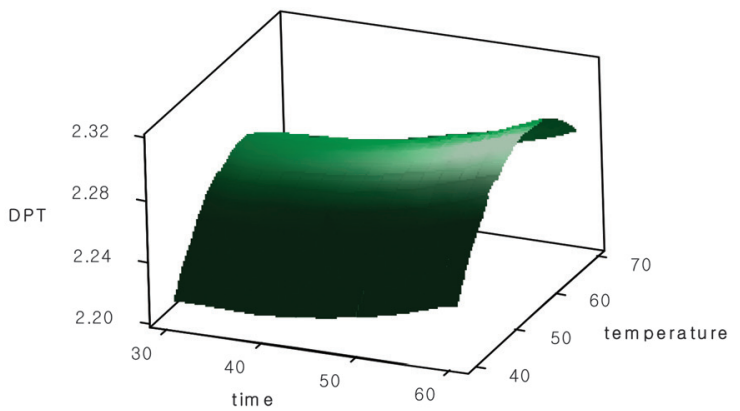

(E) Surface Plot of DPT vs temperature, percentage
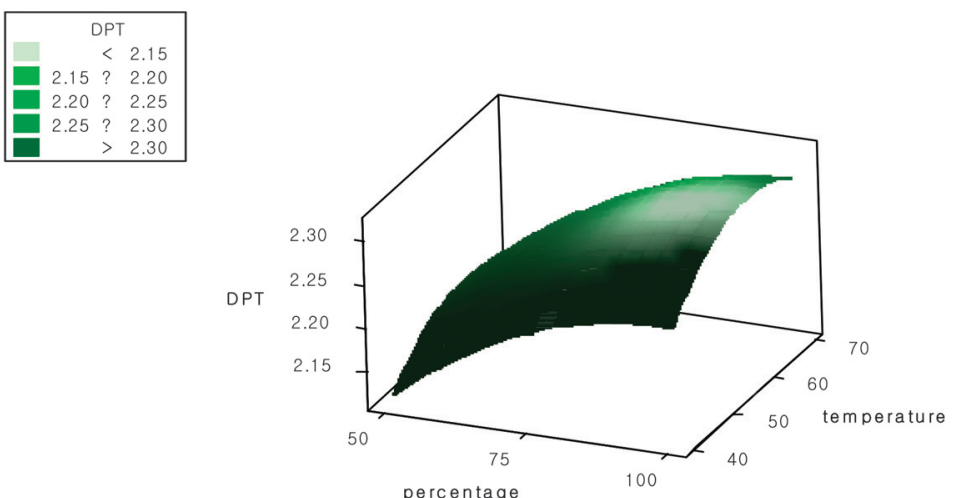

(F) Surface Plot of DPT vs percentage, time
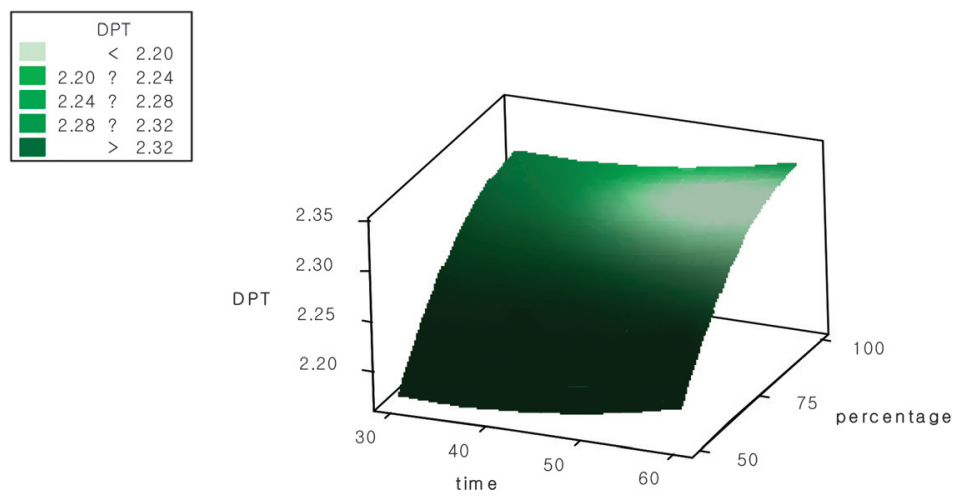

Figure 6. 2D-contour plots (A-C) and 3D surface plots (D-F) of DPT; extraction time $\left(X_{1}\right)$, solvent percentage $\left(X_{2}\right)$, and extraction temperature $\left(X_{3}\right)$

determined to be $2.341 \mathrm{mg} / \mathrm{g}$. Under the same conditions, the actual content of DPT was detected as $2.295( \pm 0.023) \mathrm{mg} / \mathrm{g}$.

\section{Conclusions}

This work shows that UPLC-PDA-QDa is a very effective method for detecting DPT. The optimum extraction conditions (i.e., extraction time, solvent percentage, and extraction temperature) for ultrasonic-assisted extraction with response surface methodology using a Box-Behnken design were determined. The ranges of these factors were selected during preliminary tests. As DPT is the main active compound in A. sylvestris roots, its optimal extraction conditions were determined. Under these optimal conditions (of $60 \mathrm{~min}, 60{ }^{\circ} \mathrm{C}$, and $100 \%$ methanol), the DPT yield was calculated as $2.341 \mathrm{mg} / \mathrm{g}$. Under the same conditions, the actual yield of DPT was determined as $2.295( \pm 0.023) \mathrm{mg} / \mathrm{g}$. Thus, the predicted yield was close to the actual yield under the same optimized extraction conditions.

\section{Conflict of Interest}

The authors declare no conflicts of interest.

\section{Compliance with Ethical Standards}

This article does not contain any studies with human or animal subjects. 


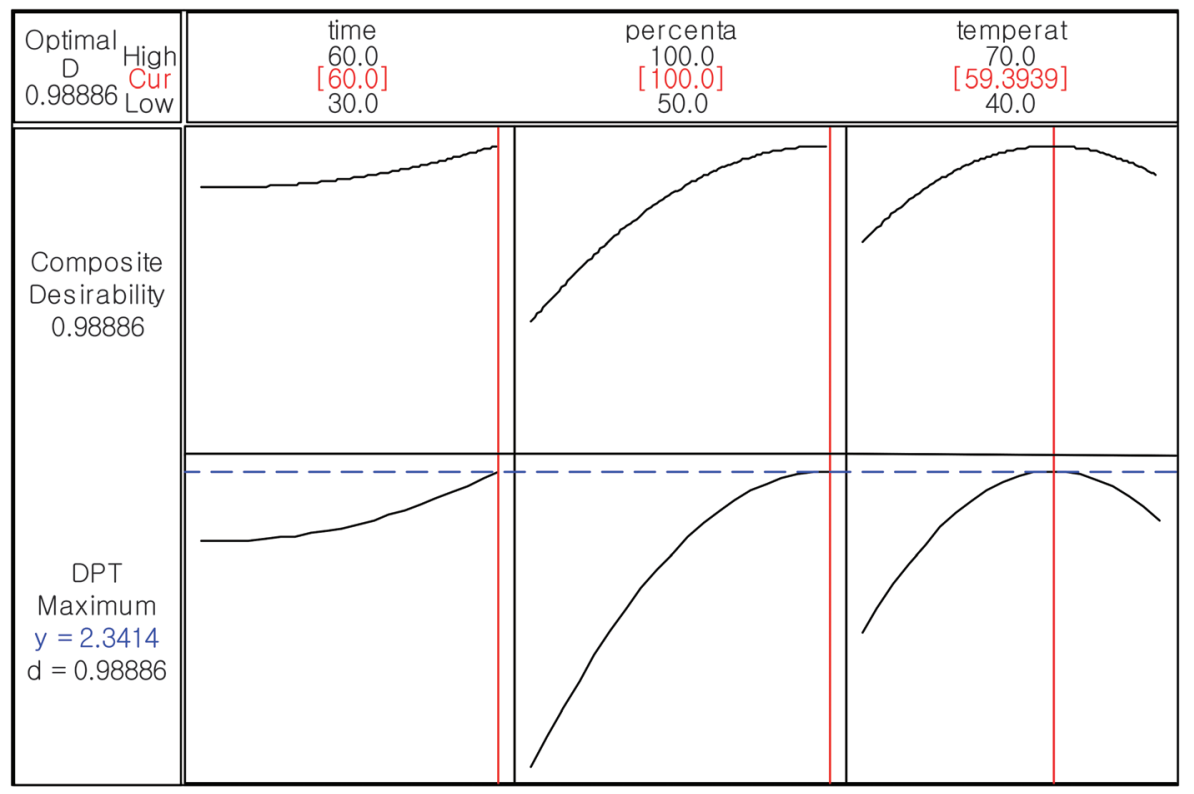

Figure 7. Optimal conditions of DPT

Acknowledgments. This study was funded by the "Evaluation of Effectiveness of Alternative Herbal Medicine Resources (K15411)" and the "Development of Foundational Techniques for the Domestic Production of Authentic Herbal Medicines based on the Establishment of Molecular Authentication System (K15420)" programs at the KIOM by the Ministry of Science, ICT, and Future Planning, South Korea.

\section{References}

1. Olaru, O. T.; Nițulescu, G. M.; Orțan, A.; Dinu-Pîrvu, C. E. Molecules 2015, 20, 15003 .

2. Bos, R.; Koulman, A.; Woerdenbag, H. J.; Quax, W. J.; Pras, N. J. Chromatogr. A 2002, 966, 233.

3. Koulman, A.; Batterman, S.; van Putten, F. M. S.; Bos, R.; Quax, W. J. Planta Med. 2003, 69, 959

4. Lin, C. X.; Lee, E.; Jin, M. H.; Yook, J.; Quan, Z.; Ha, K.; Moon, T. C.; Kim, M. J.; Kim, K. J.; Lee, S. H.; Chang, H. W. Planta Med. 2006, 72, 786.

5. Suh, S. J.; Kim, J. R.; Jin, U. H.; Choi, H. S.; Chang, Y. C.; Lee, Y. C.; Kim, S. H.; Lee, I. S.; Moon, T. C.; Chang, H. W.; Kim, C. H. Vascul. Pharm. 2009, 51, 13.

6. Tabaraki, R.; Nateghi, A. Ultrason. Sonochem. 2011, 18, 1279.

7. Kim, H. S.; Lee, A. Y.; Jo, J. E.; Moon, B. C.; Chun, J. M.; Choi, G.; Kim, H. K. Food Sci. Biotechnol. 2014, 23, 1. 813

8. Chemat, F.; Zill-e-Huma; Khan, M. K. Ultrason. Sonochem. 2011, 18,

9. Liyana-Pathirana, C.; Shahidi, F. Food Chem. 2005, 93, 47.

10. Chen, X. P.; Wang, W. X.; Li, S. B.; Xue, J. L.; Fan, L. J.; Sheng, Z. J.; Chen, Y. G. Carbohydr. Polym. 2010, 80, 944.

11. Sun, Y.; Liu, J.; Kennedy, J. F. Carbohydr. Polym. 2010, 80, 949.

12. Li, N.; Hu, Y.; Lu, Y. Z.; Zeng, R. J.; Sheng, G. P. Sci. Rep. 2016, 18 , 26115.

3. Zhong, K.; Wang, Q. Carbohydr. Polym. 2010, 80, 19.

14. Choo, B. K.; Moon, B. C.; Ji, Y.; Kim, B. B.; Choi, G.; Yoon, T.; Kim, H. K. Biol. Pharm. Bull. 2009, 32, 24

15. Lee, A. Y.; Kim, H. S.; Choi, G.; Kang, Y. M.; Kim, H. K. J. Liq. Chromatogr. Relat. Technol. 2015, 38, 1561 .

16. Li, M.; Ngadi, M. O.; Ma, Y. Food Chem. 2014, 165, 29.

17. Grosso, C.; Ferreres, F.; Gil-Izquierdo, A.; Valentão, P.; Sampaio, M.; Lima, J.; Andrade, P. B. Talant. 2014, 130, 128.

18. Prat, D.; Hayler, J.; Wells, A. Green Chem. 2014, 16, 4546.

19. Tobiszewski, M.; Tsakovski, S.; Simeonov, V.; Namiesnik, J.; Pena-Pereira, F. Green Chem. 2015, 17, 4773.

20. Elksibi, I.; Haddar, W.; Ben Ticha, M.; Gharbi, R.; Mhenni, M. F. Food Chem. 2014, 161, 345.

21. Vohra, A.; Satyanarayana, T. Process Biochem. 2002, 37, 999.

22. Yu, J.; Wang, J.; Liu, C.; Liu, Z.; Wang, Q. Int. J. Food Sci. Tech. 2012, 47, 1115 .

23. Ballard, T. S.; Mallikarjunan, P.; Zhou, K.; O'Keefe, S. F. J. Agric. Food Chem. 2009, 57, 3064.

24. Kim, H. S.; Lee, A. Y.; Jo, J. E.; Moon, B. C.; Ji, Y.; Kim, H. K. Arch Pharm. Res. 2014, 37, 1437. 